\title{
Mass spectrometric identification of dystrophin, the protein product of the Duchenne muscular dystrophy gene, in distinct muscle surface membranes
}

\author{
SANDRA MURPHY and KAY OHLENDIECK \\ Department of Biology, Maynooth University, National University of Ireland, Maynooth, Co Kildare, Ireland
}

Received March 9, 2017; Accepted June 22, 2017

DOI: 10.3892/ijmm.2017.3082

\begin{abstract}
Supramolecular membrane complexes of low abundance are difficult to study by routine bioanalytical techniques. The plasmalemmal complex consisting of sarcoglycans, dystroglycans, dystrobrevins and syntrophins, which is closely associated with the membrane cytoskeletal protein dystrophin, represents such a high-molecular-mass protein assembly in skeletal muscles. The almost complete loss of the dystrophin isoform Dp427-M and concomitant reduction in the dystrophin-associated glycoprotein complex is the underlying cause of the highly progressive neuromuscular disorder named Duchenne muscular dystrophy. This gives the detailed characterization of the dystrophin complex considerable pathophysiological importance. In order to carry out a comprehensive mass spectrometric identification of the dystrophin-glycoprotein complex, in this study, we used extensive subcellular fractionation and enrichment procedures prior to subproteomic analysis. Mass spectrometry identified high levels of full-length dystrophin isoform Dp427-M, $\alpha / \beta$-dystroglycans, $\alpha / \beta / \gamma / \delta$-sarcoglycans, $\alpha 1 / \beta 1 / \beta 2$-syntrophins and $\alpha / \beta$-dystrobrevins in highly purified sarcolemma vesicles. By contrast, lower levels were detected in transverse tubules and no components of the dystrophin complex were identified in triads. For comparative purposes, the presence of organellar marker proteins was studied in crude surface membrane preparations vs. enriched fractions from the sarcolemma, transverse tubules and triad junctions using gradient gel electrophoresis and on-membrane digestion. This involved the subproteomic assessment of various ion-regulatory proteins and excitation-contraction coupling components. The comparative profiling of skeletal muscle fractions established a relatively restricted subcellular localization of the dystrophin-glycoprotein
\end{abstract}

Correspondence to: Professor Kay Ohlendieck, Department of Biology, Maynooth University, National University of Ireland, Maynooth, Co Kildare, Ireland

E-mail:kay.ohlendieck@mu.ie

Key words: dystrobrevin, dystroglycan, dystrophin, dystrophinopathy, proteomics, sarcoglycan, sarcolemma, syntrophin, transverse tubules, triads complex in the muscle fibre periphery by proteomic means and clearly demonstrated the absence of dystrophin from triad junctions by sensitive mass spectrometric analysis.

\section{Introduction}

The study of the dynamic composition of the proteome and its adaptive modifications are of central importance for modern biomedicine. Mass spectrometry-based proteomics is the method of choice for the systematic identification of complex changes in protein constituents involved in human disease (1). Comparative cellular proteomic studies usually encompass: i) the efficient extraction of all assessable protein species from a select tissue specimen; ii) pre-fractionation steps to reduce sample complexity and enrich in low-abundance proteins; iii) large-scale protein separation using liquid chromatography and/or gel electrophoretic techniques; iv) the determination of proteins with an altered concentration or post-translational modifications due to pathological changes or adaptations; v) the unequivocal identification of protein species of interest by sensitive mass spectrometry; vi) the systems bioinformatics analysis of proteome-wide changes in relation to protein families and biological functions; and vii) independent verification analyses using immunoblotting, biochemical activity assays and/or microscopical techniques (2-4).

However, routine proteomic surveys are often complicated by a variety of biological and technical issues. This includes the considerable concentration range of protein species within complex tissue proteomes, as well as the significant differences in the physicochemical properties of individual proteins in relation to charge, size and modifications. This may lead to the underestimation of certain subtypes of proteins, such as low-abundance proteins, proteins with extensive post-translational modifications, hydrophobic proteins or high-molecular-mass proteins. In the case of one of the most frequently inherited diseases of early childhood, the neuromuscular disorder Duchenne muscular dystrophy (5-7), the comparative pathoproteomic analysis is complicated due to the dynamic nature of the skeletal muscle proteome $(8,9)$. Despite the fact that primary abnormalities in the Dmd gene, which encodes various isoforms of the protein dystrophin, cause Duchenne muscular dystrophy (10), the majority of comparative proteomic investigations have failed to detect dystrophin (11-16) due to technical issues associated with 
high-throughput proteomic analyses of supramolecular complexes from skeletal muscle tissues (17). Therefore, considerable enrichment methods have to be used to routinely identify the low-abundance and high-molecular-mass Dp427-M isoform of dystrophin by mass spectrometry (18-22).

Although it is well established that the dystrophin isoform Dp427-M is almost completely absent in dystrophic skeletal muscles (23), a variety of biochemical studies on dystrophin and its associated glycoprotein complex have resulted in contradictory findings in relation to the precise subcellular localization of this membrane cytoskeletal protein (24-28) and the status of the various dystrophin-associated glycoproteins in dystrophin-deficient fibres (29-33). Thus, to address these opposing results and establish the distribution of dystrophin in distinct muscle surface membranes by a more sensitive technique, the present study employed an advanced subproteomic profiling approach. The presence of dystrophin and its associated proteins, i.e. dystroglycans, sarcoglycans, syntrophins and dystrobrevins, was studied in the sarcolemma and transverse tubules as compared to triad junctions. Optimized pre-fractionation and affinity enrichment steps in combination with efficient on-membrane digestion (34) and mass spectrometric analysis was utilized to unequivocally identify dystrophin in isolated membrane preparations. For the assessment of subcellular cross-contaminations, the proteomic identification of established sarcolemmal proteins was compared to markers of the sarcoplasmic reticulum, transverse tubules and other organelles (35). The most important finding of this study is that the dystrophin-glycoprotein complex was shown to be enriched in the sarcolemma and this proteomic result agrees with cell biological and ultrastructural studies of dystrophin localization (36-39).

\section{Materials and methods}

Materials. Analytical grade chemicals and materials for gel electrophoresis were obtained from Amersham Biosciences/ GE Healthcare (Little Chalfont, Buckinghamshire,UK), National Diagnostics (Atlanta, GA, USA) and BioRad Laboratories (Hemel-Hempstead, Hertfordshire, UK). Protease inhibitor cocktails were purchased from Roche Diagnostics (Mannheim, Germany). Nitrocellulose membranes were from Millipore (Bedford, MA, USA). The reversible membrane stain Memcode was purchased from Thermo Fisher Scientific (Waltham, MA, USA) and sequencing grade modified trypsin was obtained from Promega (Madison, WI, USA). Liquid chromatography-mass spectrometry Chromasolv water was purchased from Fluka (Milwaukee, WI, USA). Biobasic C18 Picofrit columns were from Dionex (Sunnyvale, CA, USA) and C18 spin columns were obtained from Thermo Fisher Scientific (Dublin, Ireland). $\mathrm{N}$-acetylglucosamine agarose, Ponceau S-Red staining solution, polyvinylpyrrolidone-40 and formic acid, as well as all other analytical grade chemicals used in this study, were purchased from Sigma Chemical Company (Dorset, UK).

Skeletal muscle preparations. Adult New Zealand white rabbit hind limb and back muscle tissue was obtained as freshly dissected post-mortem specimens from the Bioresource Facility of the National University of Ireland. Rabbits were kept under standard conditions according to Irish legislation on the use of animals in experimental research. Muscle samples were immediately quick-frozen in liquid nitrogen and stored at $-80^{\circ} \mathrm{C}$ prior to usage. Frozen tissue specimens were transported to Maynooth University on dry ice in accordance with the Department of Agriculture (animal by-product register number 2016/16 to the Department of Biology, National University of Ireland, Maynooth). For the isolation of distinct surface membrane fractions, combined muscle samples were trimmed of excess fat and then minced with fine scissors on ice prior to tissue homogenization and subcellular fractionation (40). All procedures were carried out in a cold room at $4^{\circ} \mathrm{C}$ and buffers were supplemented with a protease inhibitor cocktail containing $1 \mu \mathrm{M}$ leupeptin, $0.5 \mu \mathrm{M}$ soybean trypsin inhibitor, $0.2 \mathrm{mM}$ pefabloc, $1.4 \mu \mathrm{M}$ pepstatin-A, $0.15 \mu \mathrm{M}$ aprotinin, $0.3 \mu \mathrm{M}$ E-64 and $1 \mathrm{mM}$ EDTA (41).

Subcellular fractionation of muscle membranes. Skeletal muscle homogenisation was carried out by the disruption of tissue pieces in 7 volumes of $10 \%$ (w/v) sucrose, $20 \mathrm{mM}$ Tris-maleate, $\mathrm{pH} 7.0$ and 3 mM EGTA (27) for 3 times 30 secs with the help of an Ultra-Turrax T25 homogenizer from IKA Labortechnik (Staufen, Germany). Initial differential centrifugation for the isolation of a crude micrososmal fraction was carried out by a 15 -min centrifugation step at $13,000 \mathrm{x} \mathrm{g}$, followed by filtration of the supernatant through 3 layers of cheesecloth and then a second 90-min centrifugation step at $23,400 \mathrm{x}$ g. Protein concentration was determined by the Bradford dye binding method using bovine serum albumin as a standard (42). To further fractionate the suspended total microsomal pellet (10 $\mathrm{mg}$ protein/ml), an optimized sucrose density gradient technique was employed (27). The main rationale of this approach was to efficiently separate a crude sarcolemma-enriched fraction from isolated transverse tubules and triad junctions, with a minimum cross-contamination by the highly abundant non-junctional terminal cisternae and longitudinal tubules of the sarcoplasmic reticulum and mitochondria (41,43-45). Microsomal vesicles were centrifuged at $150,000 \mathrm{x}$ g for $6 \mathrm{~h}$ through a continuous $10-60 \%(\mathrm{w} / \mathrm{v})$ sucrose gradient buffered with $25 \mathrm{mM}$ Tris-maleate, $\mathrm{pH} 7.0$ and $3 \mathrm{mM}$ EGTA using a SW-28 rotor from Beckman Coulter (Palo Alto, CA, USA). Distinct vesicle bands containing enriched fractions of the crude surface membranes, transverse tubules and triad junctions were carefully harvested and diluted 4-fold with above buffer (41). Membrane fractions were then centrifuged at $100,000 \mathrm{x} g$ for $35 \mathrm{~min}$ and their protein constituents separated by gradient gel electrophoresis. The broad band containing the non-junctional sarcoplasmic reticulum (46) and pellets with mitochondria and cellular debris were discarded.

Lectin affinity agglutination of sarcolemma vesicles. Distinct sarcolemma vesicles were further isolated from the crude surface membrane fraction by an optimized lectin affinity agglutination technique (47). Importantly, during the vesicle agglutination-deagglutionation-centrifugation procedure (27), the above-listed protease inhibitor cocktail was added to all buffer systems in order to prevent excess proteolysis of the many high-molecular-mass proteins that are present in the sarcolemma (18). Wheat germ agglutinin was extracted from crude wheat germ by the method of Vretblad (48) and purified to homogeneity by affinity chromatography using 

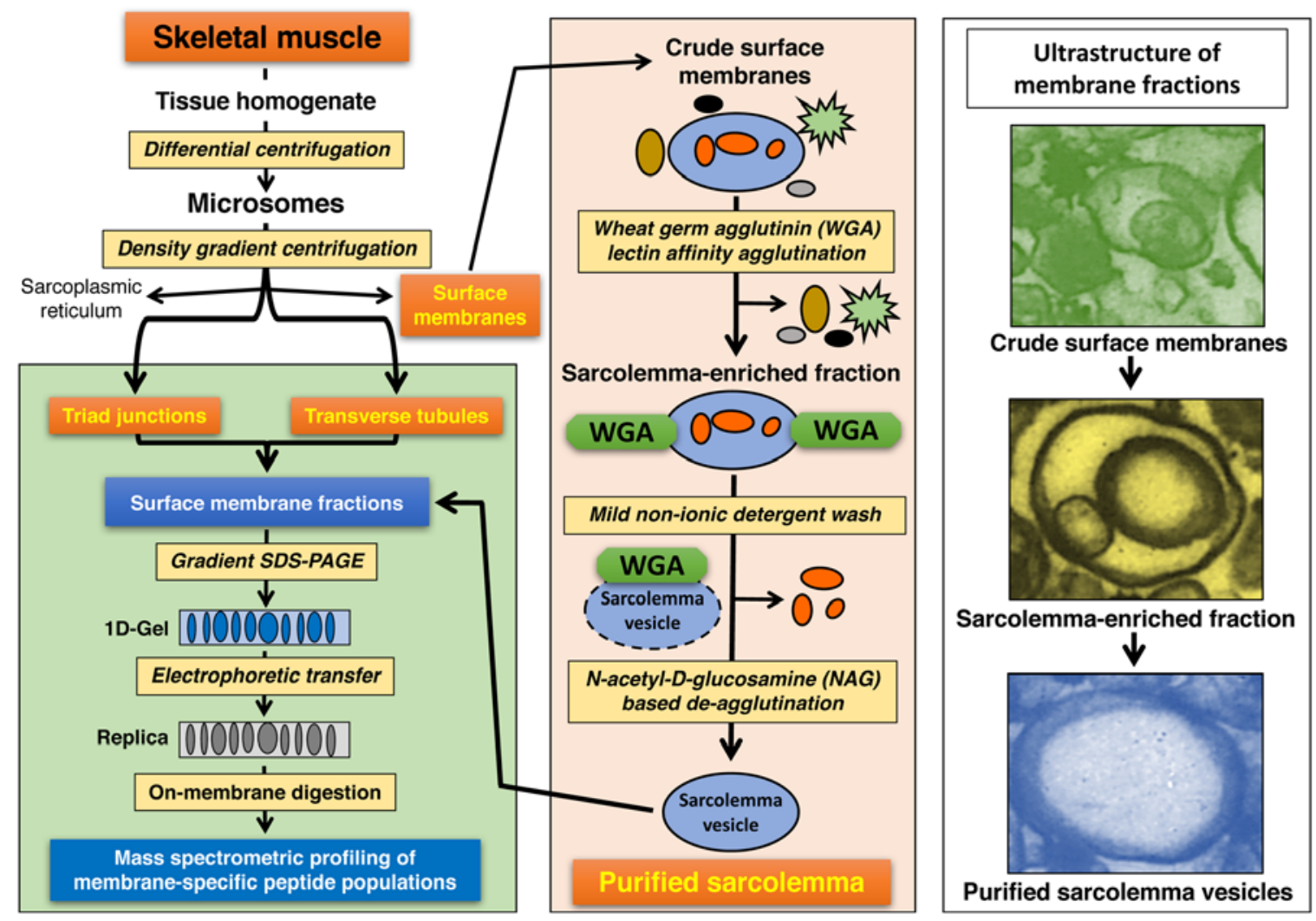

Figure 1. Flowchart of the bioanalytical strategy to determine the distribution of dystrophin and its associated glycoprotein complex in surface membranes from skeletal muscle.

$\mathrm{N}$-acetylglucosamine agarose. Purified wheat germ lectin was resuspended at a protein concentration of $1 \mathrm{mg} / \mathrm{ml}$ in $50 \mathrm{mM}$ sodium phosphate, $\mathrm{pH} 7.4,0.16 \mathrm{M} \mathrm{NaCl}$. A $30 \mathrm{ml}$ aliquote of the lectin solution was gently mixed with an equal volume of crude surface membrane vesicles $(1 \mathrm{mg}$ protein $/ \mathrm{ml})$ and incubated for $30 \mathrm{~min}$ on ice (27). The lectin agglutinated membrane suspension was centrifuged for $90 \mathrm{sec}$ at $14,000 \mathrm{x} \mathrm{g}$ and the pelleted vesicles resuspended in $20 \mathrm{mM}$ Tris-HC1, $\mathrm{pH} 7.4$ and $0.303 \mathrm{M}$ sucrose. The resuspension of agglutinated vesicles and re-centrifugation was repeated twice to remove the non-agglutinated membrane fraction, which contained mostly cellular debris and non-sarcolemmal membrane systems. Importantly, to eliminate any trapped material in the interior space of enriched sarcolemma vesicles, the fraction was mildly washed with non-ionic detergent by incubation for $10 \mathrm{~min}$ with $0.1 \%$ (v/v) Triton X.100, 0.3 M sucrose, 20 mM Tris-CI, pH 7.4 on ice (28). Detergent-treated vesicles were centrifuged for $90 \mathrm{sec}$ at 14,000 x $\mathrm{g}$ and resuspended in above buffer lacking the detergent Triton X-100. Subsequently deagglutination was carried out by incubation for $20 \mathrm{~min}$ in $18 \mathrm{ml}$ of $0.2 \mathrm{M}$ of the competitive sugar $N$-acetyl-D-glucosamine in $20 \mathrm{mM}$ Tris- $\mathrm{HCl}, \mathrm{pH} 7.4$ and $0.303 \mathrm{M}$ sucrose. The deagglutinated suspension was centrifuged at $14,000 \mathrm{x}$ g for $90 \mathrm{sec}$. The pellet consisted mostly of sarcoplasmic reticulum and transverse tubule vesicles and was discarded. The supernatant fraction containing enriched sarcolemma vesicles was then centrifuged at $150,000 \mathrm{x} \mathrm{g}$ for $20 \mathrm{~min}$ to yield a pellet with non-agglutinated and highly purified sarcolemma vesicles (27). Sarcolemma protein constituents were further separated by gradient gel electrophoresis. An overview of this comprehensive subcellular fractionation strategy is provided in the flow chart of Fig. 1.

Gradient gel electrophoresis. A 3-12\% gradient gel system with 1.5-mm-thick and 16-cm-long slab gels using a Protean IIxi Cell (BioRad Laboratories) was used to carry out sodium dodecyl sulfate polyacrylamide gel electrophoresis at a constant setting of $200 \mathrm{~V}$. Protein separation was carried out until the blue dye front had disappeared from the bottom of the gel (41). An ice bath-cooled large Transblot Cell (BioRad Laboratories) was employed to perform the electrophoretic transfer of gel-bound protein bands to nitrocellulose sheets for $90 \mathrm{~min}$ at $100 \mathrm{~V}$. The reversible protein dyes Ponceau S Red or MemCode were used to visualize the transferred proteins (14), whereby destaining was carried out with $0.9 \%$ (w/v) $\mathrm{NaCl}$ and $50 \mathrm{mM}$ sodium phosphate, $\mathrm{pH} 7.4$ (42).

On-membrane digestion of muscle proteins. In contrast to previously published procedures that have focused on the on-membrane digestion of individual protein bands $(18,46)$, in the present study, nitrocellulose membrane strips corresponding to the entire lane of proteins from individual subcellular fractions, i.e. crude surface membranes, transverse tubules, triads and highly purified sarcolemma vesicles, were used for peptide generation (34). Membrane strips were placed in $15 \mathrm{ml}$ Falcon tubes, de-stained with $0.9 \%$ (w/v) $\mathrm{NaCl}$ and $50 \mathrm{mM}$ sodium phosphate, $\mathrm{pH} 7.4$ and then washed 5 times with distilled water. The strips were subsequently blocked with $0.5 \%$ polyvinylpyrrolidone $(\mathrm{PV}-40)$ for $40 \mathrm{~min}$ at $37^{\circ} \mathrm{C}$ with 
gentle agitation (49-51). To remove excess PVP-40, membrane strips were washed extensively with distilled water and placed in new $15 \mathrm{ml}$ Falcon tubes. Reconstituted sequencing grade trypsin was added to the digestion buffer consisting of $100 \mathrm{mM}$ ammonium bicarbonate/10\% acetonitrile $(1: 1, \mathrm{v} / \mathrm{v})$. Each nitrocellulose strip was incubated with $4 \mathrm{ml}$ of this mixture, corresponding to a 1:20 ratio of trypsin to muscle protein. The strips were digested overnight at $37^{\circ} \mathrm{C}$ with agitation. Following the generation of distinct peptide populations, $4 \mathrm{ml}$ of extraction buffer (5\% formic acid/acetonitrile [1:2, v/v]) was added and strips incubated at $37^{\circ} \mathrm{C}$ for $15 \mathrm{~min}$ with agitation (52). The supernatant was subsequently transferred to $1.5 \mathrm{ml}$ micro-centrifuge tubes and dried by vacuum centrifugation (18). Dried peptides were re-suspended in $0.5 \%$ trifluoroacetic acid $/ 5 \%$ acetonitrile and centrifuged in $22-\mu \mathrm{m}$ acetate cellulose spin filter tubes for $20 \mathrm{~min}$ to remove any membrane particles (46). Peptides were then desalted using C18 spin columns (Thermo Fisher Scientific) and dried by vacuum centrifugation. Dried peptides were stored at $-80^{\circ} \mathrm{C}$ until further usage in mass spectrometric analysis.

Liquid-chromatography mass spectrometric analysis. Prior to label-free liquid chromatography mass spectrometric (LC-MS/ MS) analysis, dried peptides were re-suspended in loading buffer consisting of $2 \%$ acetonitrile and $0.05 \%$ trifluoroacetic acid in LC-MS grade water. The LC-MS/MS analysis of peptides obtained from on-membrane digestion was carried out using an Ultimate 3000 NanoLC system (Dionex Corporation, Sunnyvale, CA, USA) coupled to a Q-Exactive mass spectrometer (Thermo Fisher Scientific). Peptide mixtures were loaded by an auto-sampler onto a C18 trap column (C18 PepMap, $300 \mu \mathrm{m}$ id $\times 5 \mathrm{~mm}, 5 \mu \mathrm{m}$ particle size, 100 A pore size; Thermo Fisher Scientific). The trap column was switched on-line with an analytical Biobasic C18 Picofrit column (C18 PepMap, $75 \mu \mathrm{m}$ id $\mathrm{x} 50 \mathrm{~cm}, 2 \mu \mathrm{m}$ particle size, 100 A pore size; Dionex). Peptides were eluted using a 65 -min method over the following gradient (Solvent A: $80 \%(\mathrm{v} / \mathrm{v})$ acetonitrile and $0.1 \%(\mathrm{v} / \mathrm{v})$ formic acid in LC-MS grade water): $3 \%$ Solvent A for $5 \mathrm{~min}, 10 \%$ Solvent A for $30 \mathrm{~min}, 40 \%$ Solvent A for $5 \mathrm{~min}, 90 \%$ Solvent A for $5 \mathrm{~min}$ and $3 \%$ Solvent A for $10 \mathrm{~min}$. The column flow rate was set to $0.3 \mu \mathrm{l} / \mathrm{min}$. Data were acquired with Xcalibur software (Thermo Fisher Scientific). The Q-Exactive mass spectrometer was operated in positive, data-dependent mode and was externally calibrated. Survey MS scans were conducted in the $300-1,700 \mathrm{~m} / \mathrm{z}$ range with a resolution of $140,000(\mathrm{~m} / \mathrm{z} 200)$ and a lock mass of 445.12003. Collision-induced dissociation (CID) fragmentation was carried out with the fifteen most intense ions per scan and at 17,500 resolution. A dynamic exclusion window was applied within $30 \mathrm{sec}$ (53). An isolation window of $2 \mathrm{~m} / \mathrm{z}$ and one microscan were used to collect suitable tandem mass spectra.

Data analysis. Mass spectrometry raw files were processed using the Proteome Discoverer 1.4 (Thermo Fisher Scientific) software with Sequest HT as the search engine and the UniProt sequence database. The following search parameters were used for protein identification: i) peptide mass tolerance set to $10 \mathrm{ppm}$; ii) $\mathrm{MS} / \mathrm{MS}$ mass tolerance set to $0.5 \mathrm{Da}$; iii) up to two missed cleavages; iv) carbamidomethylation set as a fixed modification; and v) methionine oxidation set as a variable modification (14). Since the rabbit genome is incomplete, mass spectrometry raw files were searched against both the Oryctolagus cuniculus database and the Mammalia database (54). Peptides were filtered using a minimum XCorr score of 1.5 for $1,2.0$ for $2,2.25$ for 3 and 2.5 for 4 charge states, with peptide probability set to high confidence. For inclusion into Tables I-IV, identified proteins had to meet a minimum inclusion criteria of $\geq 2$ peptides and a coverage $\geq 5 \%$.

\section{Results}

Skeletal muscle membrane proteomics. The systematic enrichment of distinct muscle membrane fractions across an optimized separation scheme was used to perform a detailed subproteomic analysis of core members of the dystrophin-glycoprotein complex. The proteomic profile of the full-length dystrophin isoform, Dp427-M, was compared to the subcellular localization of established protein markers of the sarcolemma, transverse tubules and triad junctions. In addition, the presence of marker proteins representative of the highly abundant sarcoplasmic reticulum, as well as the contractile apparatus, mitochondria and other major types of muscle organelles was evaluated by mass spectrometric analysis. The present study was carried out on rabbit skeletal muscle, since relatively large amounts of tissue were needed as starting material for the extensive subcellular fractionation and biochemical enrichment procedures prior to on-membrane digestion of proteins and mass spectrometry, particularly in relation to the sarcolemma-enriched fraction.

The affinity lectin agglutination technique requires a considerable amount of membrane material for a successful enrichment of sarcolemma vesicles $(28,47)$. Since this procedure was originally optimized using rabbit muscle tissue (27), we selected the same animal species for this comprehensive proteomic profiling of the dystrophin complex. Muscle biopsy samples from human patients would have been too small to produce a suitable tissue homogenate for extensive subcellular fractionation studies, as judged by our earlier experience with analysing patient specimens (30,55-58). A major finding of our study is that dystrophin and its associated glycoprotein complex are highly enriched in the surface membrane and are apparently absent from the triad junctions. Thus, future proteomic studies comparing normal vs. dystrophic human muscles, where only restricted amounts of tissue are available, should ideally focus on the sarcolemma-enriched fraction.

Subproteomic profiling of skeletal muscle membranes. The diagram in Fig. 2 outlines the subproteomic profiling approach used in this study to assign the dystrophin-glycoprotein complex to specific subcellular localisations in skeletal muscle. Skeletal muscle microsomes were isolated by differential centrifugation and further separated into distinct fractions enriched in crude surface membranes, transverse tubules and triads by density gradient centrifugation (27). For the detailed evaluation of the muscle plasma membrane, an elaborate lectin affinity agglutination method was employed to isolate highly purified sarcolemma vesicles that exhibit a minimum contamination with components derived from the sarcoplasmic reticulum and other abundant organelles $(28,47)$. An on-membrane digestion method was used for the optimum 
Table I. Mass spectrometry-based subproteomic profiling of sarcolemma marker proteins in surface membrane fractions from rabbit skeletal muscle.

\begin{tabular}{llccrc}
\hline $\begin{array}{l}\text { Organellar } \\
\text { marker protein }\end{array}$ & Gene no. & $\begin{array}{c}\text { Surface membrane } \\
\text { peptides (coverage) }\end{array}$ & $\begin{array}{c}\text { Sarcolemma peptides } \\
\text { (coverage) }\end{array}$ & $\begin{array}{c}\text { Transverse tubules } \\
\text { peptides (coverage) }\end{array}$ & $\begin{array}{c}\text { Triads peptides } \\
\text { (coverage) }\end{array}$ \\
\hline$\alpha-\mathrm{Na}^{+} / \mathrm{K}^{+}$-ATPase & ATP1A2 & $15(19.0 \%)$ & $30(32.2 \%)$ & $21(26.7 \%)$ & - \\
$\beta-\mathrm{Na}^{+} / \mathrm{K}^{+}$-ATPase & ATP1B1 & - & $3(11.9 \%)$ & $5(23.8 \%)$ & - \\
$\mathrm{PMCA} \mathrm{Ca}^{2+}$-ATPase & ATP2B1 & $6(8.3 \%)$ & $14(14.6 \%)$ & $15(16.7 \%)$ & - \\
$\beta-$ Integrin & ITGB1 & $7(11.9 \%)$ & $7(11.0 \%)$ & $8(13.8 \%)$ & - \\
\hline
\end{tabular}

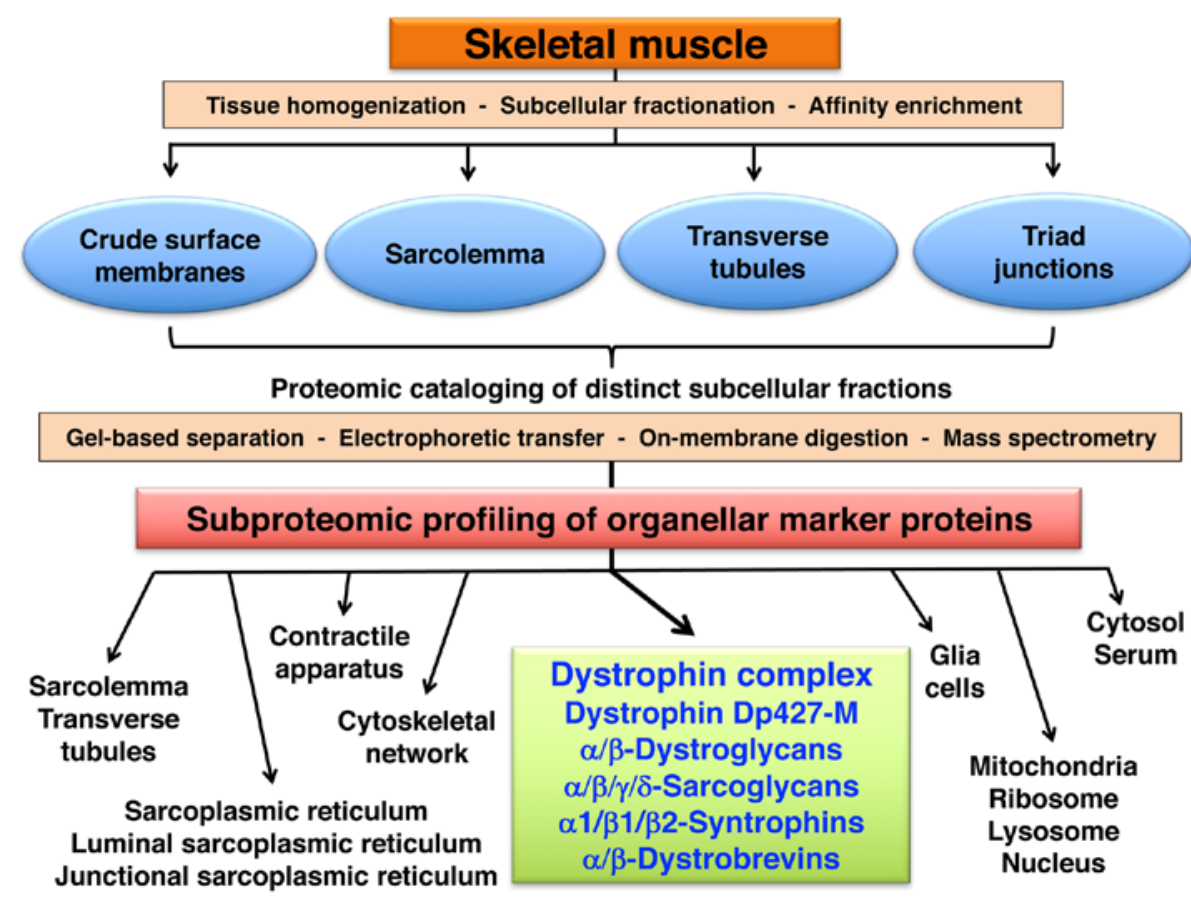

Figure 2. Overview of the subproteomic profiling of organellar marker proteins from skeletal muscle tissue.

generation of representative peptide populations from the different membrane fractions $(18,34,46)$. The raw data files from the mass spectrometric analysis were searched against the Oryctolagus cuniculus database. However, the rabbit genome is incomplete and we therefore had to supplement the data analysis by also screening the Mammalia database, as previously described by Liu et al (54).

Following initial database searches, the identified proteins were filtered extensively. For inclusion in tables with significant proteomic hits, the identification of individual muscle protein species had to strictly meet the following inclusion criteria: i) number of peptides $\geq 2$; ii) sequence coverage $\geq 5 \%$; iii) identification by peptides that were filtered using a minimum XCorr score of 1.5 for 1, 2.0 for 2, 2.25 for 3 and 2.5 for 4 charge states; and iv) peptide probability with high confidence. Detailed information on peptide lists for the crude surface membrane, transverse tubules, triads and sarcolemma can be viewed as supplementary material on the publicly available online digital repository named Figshare (https:// figshare.com) with the file name 'Peptide Lists for crude surface membrane, transverse tubules, triads and sarcolemma' (doi: 10.6084/m9.figshare.4906436).
Mass spectrometric identification of subcellular markers in surface membrane preparations. Prior to the identification of the dystrophin-glycoprotein complex in distinct subcellular fractions from skeletal muscle, the subproteomic assessment of established ion-regulatory proteins and excitation-contraction coupling components of the crude surface membrane, sarcolemma and transverse tubules was carried out. Following mass spectrometry, the data analysis of sarcolemma identified 566 proteins when searched against the rabbit database of which 330 protein species had $\geq 2$ unique peptides. A total of 784 proteins were established when searched against the amniota database with 316 proteins that exhibited $\geq 2$ unique peptides. The analysis of transverse tubules revealed 675 proteins when searched against the rabbit database of which 374 proteins had $\geq 2$ unique peptides. The searched of the amniota database revealed 907 proteins of which 377 proteins $\mathrm{had} \geq 2$ unique peptides.

Marker proteins of the muscle surface, such as the major $\alpha$-subunit of the $\mathrm{Na}^{+} / \mathrm{K}^{+}$-ATPase, the sarcolemmal PMCA isoform of the $\mathrm{Ca}^{2+}$-pumping ATPase and $\beta$-integrin were all identified in crude membrane preparations and shown to be enriched in the sarcolemma, as well as the transverse 
Table II. Mass spectrometry-based subproteomic profiling of transverse tubules marker proteins in surface membrane fractions from rabbit skeletal muscle.

\begin{tabular}{llcccc}
\hline & Gene no. & $\begin{array}{c}\text { Surface } \\
\text { membrane peptides } \\
\text { (coverage) }\end{array}$ & $\begin{array}{c}\text { Sarcolemma } \\
\text { peptides } \\
\text { (coverage) }\end{array}$ & $\begin{array}{c}\text { Transverse } \\
\text { tubules peptides } \\
\text { (coverage) }\end{array}$ & $\begin{array}{c}\text { Triads peptides } \\
\text { (coverage) }\end{array}$ \\
\hline $\begin{array}{l}\alpha / \delta 1 \text {-voltage-dependent } \mathrm{Ca}^{2+} \text {-channel } \\
\alpha 1 \mathrm{~S} \text {-voltage-dependent } \mathrm{Ca}^{2+} \text {-channel }\end{array}$ & CACNA2D1 & $18(23.9 \%)$ & $19(21.2 \%)$ & $33(36.2 \%)$ & $10(14.6 \%)$ \\
$\beta 1$-voltage-dependent $\mathrm{Ca}^{2+}$-channel & CACNB1S & - & - & $27(14.8 \%)$ & - \\
\hline
\end{tabular}

Table III. Mass spectrometry-based subproteomic profiling of sarcoplasmic reticulum marker proteins in surface membrane fractions from rabbit skeletal muscle.

\begin{tabular}{llcrrr}
\hline Organellar marker protein & Gene no. & $\begin{array}{c}\text { Surface } \\
\text { membrane peptides } \\
\text { (coverage) }\end{array}$ & $\begin{array}{c}\text { Sarcolemma } \\
\text { peptides } \\
\text { (coverage) }\end{array}$ & $\begin{array}{c}\text { Transverse } \\
\text { tubules peptides } \\
\text { (coverage) }\end{array}$ & $\begin{array}{c}\text { Triads peptides } \\
\text { (coverage) }\end{array}$ \\
\hline Ryanodine receptor $\mathrm{Ca}^{2+}$-release channel & RyR1 & $31(8.9 \%)$ & $29(6.9 \%)$ & $65(18.3 \%)$ & $40(10.9 \%)$ \\
Fast SERCA1 Ca ${ }^{2+}$-ATPase & ATP2A1 & $39(35.8 \%)$ & $53(38.4 \%)$ & $55(48.3 \%)$ & $38(36.7 \%)$ \\
Calsequestrin-1 & CASQ1 & $6(26.3 \%)$ & $7(18.5 \%)$ & $5(17.7 \%)$ & $5(21.5 \%)$ \\
Sarcalumenin-2 & SRL-2 & $5(16.7 \%)$ & $9(15.3 \%)$ & $22(37.2 \%)$ & $4(12.5 \%)$ \\
\hline
\end{tabular}

tubules (Table I). Mass spectrometric analysis also established the minor $\beta$-subunit of the $\mathrm{Na}^{+} / \mathrm{K}^{+}$-ATPase being present in the sarcolemma membrane and its invaginations. In stark contrast, these surface membrane markers were shown to be absent from enriched triad preparations (Table I). Distinct subunits of the voltage-sensing protein complex of the transverse tubules, often referred to as the dihydropyridine receptor, were used as marker proteins of surface membrane invaginations. The $\alpha 2 / \delta 1-$ and $\beta 1$-subunits of the voltage-dependent $\mathrm{Ca}^{2+}$-channel were shown to be present in crude surface preparations, sarcolemma vesicles and triad junctions, but mass spectrometry showed their highest coverage in purified transverse tubules (Table II). Of note, the major $\alpha 1 S$-subunit of the dihydropyridine receptor was only identified in the transverse tubular fraction (by 27 peptides and a $14.8 \%$ sequence). The stringent criteria of a minimum of $5 \%$ sequence coverage used in the present study excluded the listing of the principal ion channel subunit in relation to other membrane types. The $\alpha 1 \mathrm{~S}$-subunit was only covered by $3.8 \%$ (5 peptides), $4.7 \%$ ( 7 peptides) and $3.2 \%$ (5 peptides) sequence in crude surface membranes, purified sarcolemma vesicles and triad junctions, respectively.

These subproteomic findings indicate a reasonable separation of different surface membrane fractions by the subcellular fractionation protocol employed in this investigation. Importantly, various cytoskeletal markers were shown to be present in the sarcolemmal fraction, including ankyrin-1 (ANK1, 3 peptides, $3.6 \%$ coverage), $\beta$-tubulin (TUBB, 14 peptides, $28.4 \%$ coverage), desmin (DES, 26 peptides, $52.0 \%$ coverage) and vimentin (VIME, 11 peptides, $29.0 \%$ coverage). Therefore, the linkage of the subsarcolemmal membrane cytoskeleton to the general cytoskeletal network appears to have been preserved during membrane fractio nation. This is a crucial finding in relation to the subsequent mass spectrometric analysis of the membrane cytoskeletal protein dystrophin.

Mass spectrometric identification of abundant organelles in purified sarcolemma. Since the sarcoplasmic reticulum is by far the most abundant membrane system in skeletal muscle, the presence of key marker proteins of junctional triad sites, longitudinal tubules and the lumen of the sarcoplasmic reticulum was evaluated. As listed in Table III, a considerable amount of sarcoplasmic reticulum proteins is associated with purified sarcolemma vesicles. This included the RyR1 isoform of the junctional ryanodine receptor $\mathrm{Ca}^{2+}$-release channel, the CSQ1 isoform of the luminal $\mathrm{Ca}^{2+}$-binding protein calsequestrin, the SRL-2 isoform of the $\mathrm{Ca}^{2+}$-shuttle protein sarcalumenin and the fast SERCA1 type of the $\mathrm{Ca}^{2+}$-pumping ATPase of the longitudinal tubules and terminal cisternae region. Hence, despite extensive subcellular fractionation by differential centrifugation and density gradient ultracentrifugation, as well as lectin affinity agglutination and mild detergent washing, a certain degree of cross-contamination of sarcolemma preparations by the abundant sarcoplasmic reticulum could not be avoided. Besides sarcoplasmic reticulum proteins, markers of other organelles or subcellular structures could also be identified as being present in purified sarcolemma vesicles.

This included cross-contamination with the contractile apparatus markers myosin heavy chain MyHC-IIb (MYH2B, 23 peptides, $13.4 \%$ coverage), myosin light chain MLC2 (MYLPF, 8 peptides, $55.3 \%$ coverage), tropomyosin $\alpha 1$-TM (TPM1, 14 peptides, 33.2\% coverage) and $\alpha$-actin (ACTA1, 20 peptides, $55.2 \%$ coverage), the mitochondrial markers succinate dehydrogenase (SDHA, 6 peptides, $14.2 \%$ coverage), aconitate hydratase (ACO2, 8 peptides, $13.0 \%$ coverage) and cytochrome $c$ oxidase subunit 2 (COX2, 4 peptides, 
Table IV. Subcellular localization of dystrophin isoform Dp427-M and its tightly associated glycoprotein-complex in rabbit skeletal muscle using liquid chromatography/mass spectrometry-based proteomics.

\begin{tabular}{llcccc}
\hline $\begin{array}{l}\text { Member of the dystrophin- } \\
\text { glycoprotein complex }\end{array}$ & Gene no. & $\begin{array}{c}\text { Surface membrane } \\
\text { peptides (coverage) }\end{array}$ & $\begin{array}{c}\text { Enriched sarcolemma } \\
\text { peptides (coverage) }\end{array}$ & $\begin{array}{c}\text { Transverse tubules } \\
\text { peptides (coverage) }\end{array}$ & $\begin{array}{c}\text { Triad junction } \\
\text { peptides (coverage) }\end{array}$ \\
\hline $\begin{array}{l}\text { Dystrophin, Dp427-M } \\
\alpha / \beta-\text { Dystroglycan }\end{array}$ & DMD & $9(10.6 \%)$ & $17(16.4 \%)$ & $8(9.0 \%)$ & - \\
$\alpha$-Sarcoglycan & DAG1 & - & $7(6.4 \%)$ & $3(5.3 \%)$ & - \\
$\beta$-Sarcoglycan & SGCA & $6(24.0 \%)$ & $9(23.0 \%)$ & $4(13.4 \%)$ & - \\
$\gamma$-Sarcoglycan & SGCB & $3(18.9 \%)$ & $8(35.9 \%)$ & $2(14.9 \%)$ & - \\
$\delta$-Sarcoglycan & SGCG & $3(16.5 \%)$ & $6(27.5 \%)$ & $4(17.2 \%)$ & - \\
$\alpha 1$-Syntrophin & SGCD & $3(16.5 \%)$ & $10(35.3 \%)$ & $4(22.8 \%)$ & - \\
$\beta 1$-Syntrophin & SNTA1 & $4(13.5 \%)$ & $8(24.2 \%)$ & $4(13.5 \%)$ & - \\
$\beta 2-$ Syntrophin & SNTB1 & $9(26.1 \%)$ & $20(42.8 \%)$ & $7(16.9 \%)$ & - \\
$\alpha$-Dystrobrevin & SNTB2 & - & $8(17.7 \%)$ & - & - \\
$\beta$-Dystrobrevin & DTNA & $4(9.8 \%)$ & $10(20.8 \%)$ & $3(12.2 \%)$ & - \\
\hline
\end{tabular}

$14.5 \%$ coverage), the ribosomal marker elongation factor $1-\alpha 2$ (EEF1A2, 4 peptides, $11.2 \%$ coverage), the lysosomal marker lysosome-associated membrane glycoprotein 1 (LAMP1, 2 peptides, $5.9 \%$ coverage), the cytosolic marker enzymes aldolase (ALDOA, 16 peptides, $42.9 \%$ coverage) and glyce raldehyde-3-phosphate dehydrogenase (GAPDH, 6 peptides, $21.0 \%$ coverage), the nucleus marker lamin-A (LMNA, 3 peptides, $6.2 \%$ coverage), the glia cell marker myelin basic protein (MBP, 7 peptides, $24.2 \%$ coverage) and the serum markers $\beta$-haemoglobin (HBB2, 2 peptides, $15.7 \%$ coverage) and albumin (ALB, 9 peptides, $12.2 \%$ coverage). Thus, lectin affinity agglutinated surface membranes are highly enriched in sarcolemma vesicles, but also contain a considerable amount of cross-contaminating protein populations derived from the contractile apparatus, mitochondria, ribosomes, lysosomes, cytosol, nucleus, glia cells and serum.

Subproteomic localization of dystrophin and its associated glycoprotein complex. Following the mass spectrometric characterization of marker proteins in the subcellular fractions enriched in the sarcolemma, transverse tubules and triad junctions, the proteomic identification of dystrophin isoform Dp427-M and the core members of the dystrophin-associated glycoprotein complex was carried out. Table IV lists the findings from the comprehensive LC-MS/MS analysis of the purified sarcolemma fraction vs. other membrane preparations. Major components of the dystrophin-glycoprotein complex, with the exception of dystroglycans and sarcospan, were identified in crude surface membranes. The lack of dystroglycan and sarcospan recognition is probably due to high glycosylation levels and extreme hydrophobicity of these dystrophin-associated proteins, respectively, which often complicates their routine proteomic identification. However, the characterization of sarcolemma preparations clearly showed a high level of coverage of the core dystrophin complex, including dystrophin, dystroglycans, sarcoglycans, syntrophins and dystrobrevins (Table IV). Representative mass spectra of 2 peptides derived from the digested dystrophin molecule in the sarcolemma-enriched fraction are shown in Fig. 3. Detailed information on MS/MS data of dystrophin, sarcoglycan, dystrobrevin and syntrophin can be viewed as supplementary material on the publicly available online digital repository named Figshare (https://figshare. com) with file name 'Mass spectra of alpha dystrobrevin, beta syntrophin, alpha sarcoglycan and dystrophin' (doi: 10.6084/ m9.figshare.4906448).

In contrast to the high levels of the membrane cytoskeletal protein Dp427-M and the $\alpha / \beta$-dystroglycan subcomplex in sarcolemma, a lower coverage was found in transverse tubules and no presence in triads. In addition, $\alpha-, \beta-, \gamma-$ and $\delta$-sarcoglycans were shown to be enriched in sarcolemma vesicles and absent from triad junctions. A minor component of the sarcoglycan complex, $\varepsilon$-sarcoglycan (SGCE), is not listed, since it was identified by only 1 peptide (5.8\% coverage) in the sarcolemma. Cytosolic binding partners of dystrophin, $\alpha 1 / \beta 1 /$ $\beta 2$-syntrophins and $\alpha / \beta$-dystrobrevins, were also shown to be present at high coverage in sarcolemma vesicles (Table IV). In contrast, lower levels were detected in transverse tubules and none were identified in the enriched triad fraction.

\section{Discussion}

Subcellular fractionation in combination with mass spectro metry is a powerful biochemical tool to catalogue organellar proteomes and compare the composition of distinct subproteomes (59-61). The partial separation of organelles and affinity purification of distinct membrane vesicles across an optimized fractionation scheme, coupled with sensitive protein identification techniques, can also be extremely helpful for the prediction of protein subcellular localisation (62). Here, we used such an approach with a combination of subcellular fractionation, gradient gel electrophoresis, on-membrane digestion and mass spectrometry to assign the dystrophin isoform, Dp427-M, and its tightly associated glycoprotein complex to specific subcellular localisations in skeletal muscles.

The protein constituents of distinct subcellular fractions from skeletal muscle have previously been identified by a variety of comprehensive subproteomic studies (35). This has included systematic proteomic cataloguing approaches or the more focused mass spectrometric characterization of subsets of 


\section{QLGEVASFGGSNIEPSVR}
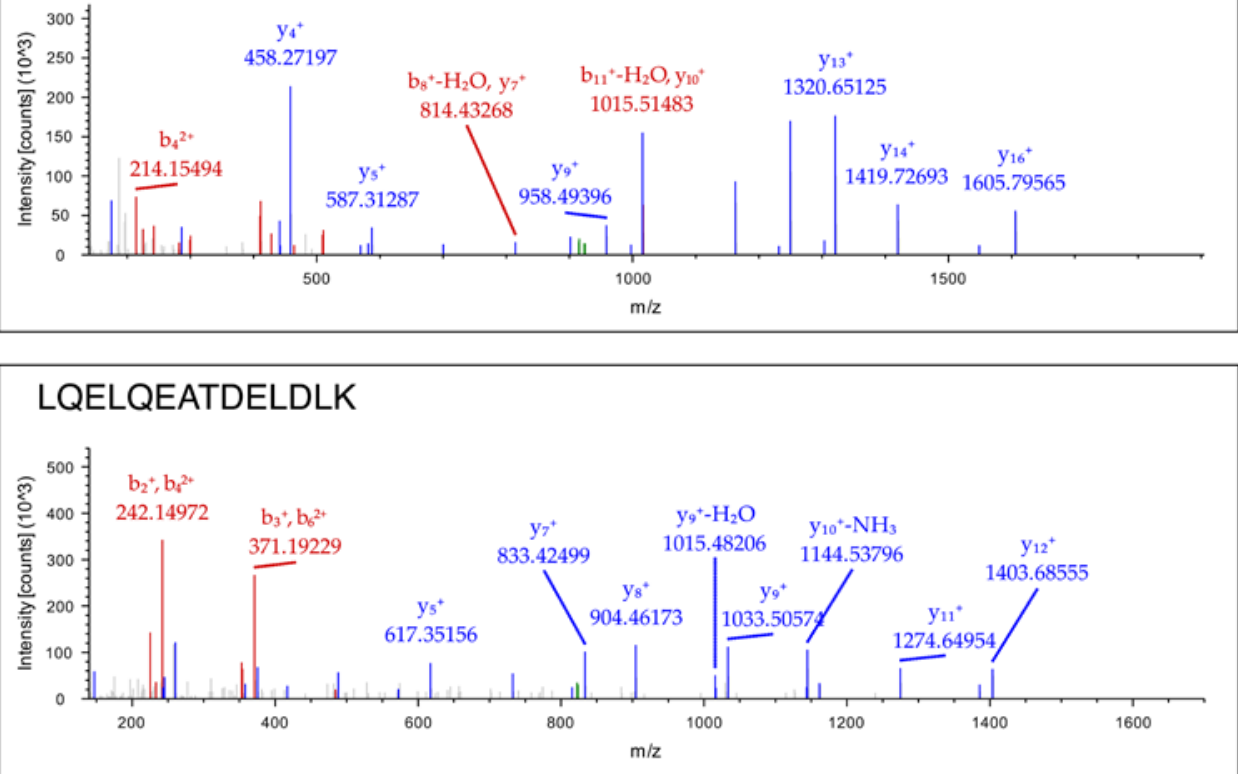

Figure 3. Proteomic identification of the membrane cytoskeletal protein dystrophin in the sarcolemma-enriched fraction from skeletal muscle. Shown are representative mass spectra of 2 peptides derived from the digested dystrophin molecule.

\section{Subproteomic Profile of Dystrophin Complex}

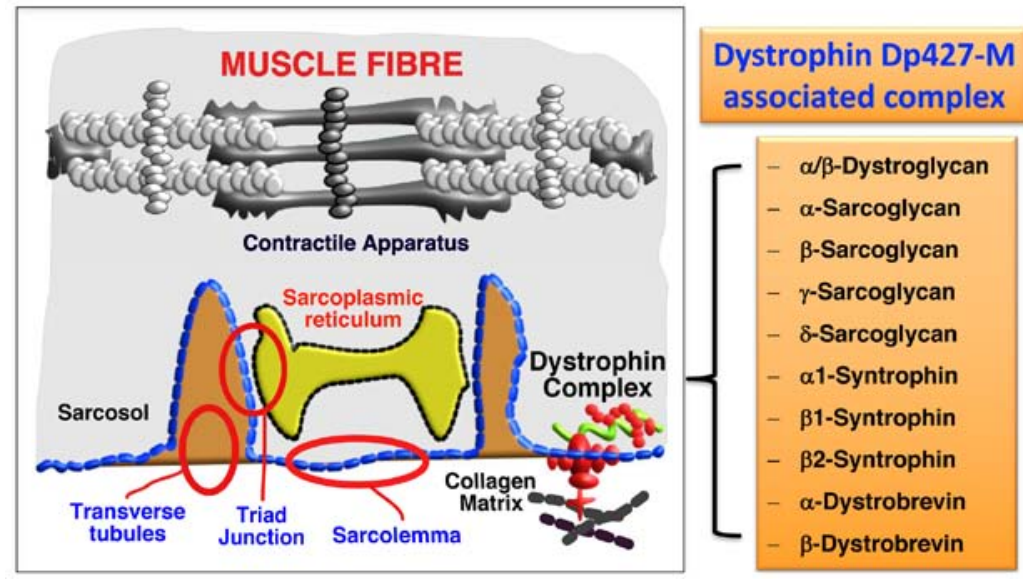

Figure 4. Diagrammatic presentation of the findings from the subproteomic profiling of the dystrophin-glycoprotein complex from skeletal muscle.

proteins in mitochondria (63-65), contact zones between mitochondria and the sarcoplasmic reticulum (66), the unconjugated sarcoplasmic reticulum $(46,67)$, nuclei $(68)$, plasmalemma (18), cytosol (69-71) and the contractile apparatus (72,73). Building on these protein databases, it is possible to evaluate the findings from new proteomic screening surveys of subcellular fractions.

The purified sarcolemma vesicles studied in this report by mass spectrometry showed a high content of surface membrane markers such as the $\alpha$-subunit of the $\mathrm{Na}^{+} / \mathrm{K}^{+}$-ATPase and the sarcolemmalPMCA isoform of the $\mathrm{Ca}^{2+}$-ATPase, which suggests a considerable enrichment of plasma membrane structures by lectin affinity agglutination (27). This in turn demonstrates that dystrophin and its associated glycoproteins are highly enriched in the sarcolemma of skeletal muscle fibres $(36-39,74)$ and not as initially assumed in the triad junctions $(24,25)$. However, almost all subcellular fractionation studies are complicated by a certain degree of cross-contamination by abundant membrane systems. This is probably due to complex alterations that occur during tissue homogenization and subcellular fractionation steps, including i) protein desorption/adsorption processes; ii) the entrapment of proteins and smaller vesicles in larger membrane vesicles; and iii) the formation of mixtures of membrane sheets, inside-out vesicles and right-side-out vesicles. In skeletal muscles, especially the sarcoplasmic reticulum with its high density of $\mathrm{Ca}^{2+}$-regulatory proteins (75), as recently confirmed by subproteomic profiling studies $(46,67)$, is often present in purified vesicle preparations of other organelles. This was also shown to be the case in this study. However, 
despite the fact that the purified sarcolemma fraction contains a certain degree of other abundant membrane systems, the dystrophin-glycoprotein was clearly shown to be enriched in the sarcolemma membrane.

The key findings from the mass spectrometry-based subproteomic survey presented in this report are summarized in Fig. 4, showing diagrammatically the subcellular localization of most of the components of the dystrophin-glycoprotein complex in the sarcolemma. This is based on the high sequence coverage of dystrophin isoform Dp427-M, $\alpha / \beta$-dystroglycan, $\alpha$-sarcoglycan, $\beta$-sarcoglycan, $\gamma$-sarcoglycan, $\delta$-sarcoglycan, $\alpha 1$-syntrophin, $\beta 1$-syntrophin, $\beta 2$-syntrophin, $\alpha$-dystrobrevin and $\beta$-dystrobrevin, as determined by mass spectrometric analysis. Thus, with the exception of the minor and highly hydrophobic dystrophin-associated protein named sarcospan, all other core elements of the dystrophin complex were unequivocally identified by subproteomic means. This included the integral glycoprotein $\beta$-dystroglycan as the direct cytoskeletal linker of dystrophin to the plasmalemma, in conjunction with the extracellular laminin-binding protein $\alpha$-dystroglycan. The main subunits of the integral sarcoglycan subcomplex, consisting of $\alpha-, \beta-, \gamma$ - and $\delta$-subunits, were also shown to be enriched in the sarcolemma. Furthermore the cytosolic binding partners of full-length muscle dystrophin, i.e. $\alpha 1 / \beta 1 /$ $\beta 2$-syntrophins and $\alpha / \beta$-dystrobrevins, were clearly identified in the subfractionated plasmalemma.

In conclusion, the dystrophin-glycoprotein complex was unequivocally shown to be highly enriched in the sarcolemma fraction and appears to exist at a lower density in the transverse tubular part of the surface membrane. In agreement with extensive cell biological and ultrastructural studies (36-39), dystrophin and its associated glycoprotein complex seem to be absent from triads. Thus, the sensitive subproteomic analysis presented in this study could clearly establish a restricted subcellular localization of dystrophin, which may be of considerable biomedical importance for future comparative investigations into the molecular pathogenesis of X-linked muscular dystrophy. Forthcoming studies with human biopsy samples can now build on these subproteomic findings and attempt to isolate sarcolemma-enriched fractions from dystrophic vs. normal human muscles. Using highly sensitive mass spectrometry, the comparative proteomic profiling of skeletal muscle specimens from Duchenne patients may identify new dystrophin-associated protein species and protein-protein interaction patterns within the surface membrane and its associated sub-sarcolemmal cytoskeleton. The biochemical and cell biological characterization of the dystrophin complex and its wider network of binding proteins in human muscles should establish new biomarker candidates for improving diagnostic, prognostic and therapy-monitoring approaches in X-linked muscular dystrophy.

\section{Acknowledgements}

The present study was supported by a Hume scholarship from Maynooth University and project grants from Muscular Dystrophy Ireland and the Irish Health Research Board (HRB/MRCG-2016-20). The Q-Exactive quantitative mass spectrometer was funded under the Research Infrastructure Call 2012 by Science Foundation Ireland (SFI-12/RI/2346/3).
The authors would like to thank Dr Paul Dowling and Ms. Caroline Batchelor for expert technical support and for help with data analysis.

\section{References}

1. Cifani P and Kentsis A: Towards comprehensive and quantitative proteomics for diagnosis and therapy of human disease. Proteomics 17: Jan 2017 (Epub ahead of print).

2. Angel TE, Aryal UK, Hengel SM, Baker ES, Kelly RT, Robinson EW and Smith RD: Mass spectrometry-based proteomics: Existing capabilities and future directions. Chem Soc Rev 41: 3912-3928, 2012.

3. Van Riper SK, de Jong EP, Carlis JV and Griffin TJ: Mass spectrometry-based proteomics: Basic principles and emerging technologies and directions. Adv Exp Med Biol 990: 1-35, 2013.

4. Zhang Z, Wu S, Stenoien DL and Paša-Tolić L: High-throughput proteomics. Annu Rev Anal Chem (Palo Alto, Calif) 7: 427-454, 2014.

5. Allen DG, Whitehead NP and Froehner SC: Absence of dystrophin disrupts skeletal muscle signaling: Roles of $\mathrm{Ca}^{2+}$ reactive oxygen species, and nitric oxide in the development of muscular dystrophy. Physiol Rev 96: 253-305, 2016.

6. Holland A, Murphy S, Dowling $\mathrm{P}$ and Ohlendieck K: Pathoproteomic profiling of the skeletal muscle matrisome in dystrophinopathy associated myofibrosis. Proteomics 16: 345-366, 2016.

7. Ohlendieck K and Swandulla D: Molecular pathogenesis of Duchenne muscular dystrophy-related fibrosis. Pathologe 38: 21-29, 2017 (In German).

8. Murphy S and Ohlendieck K: The biochemical and mass spectrometric profiling of the dystrophin complexome from skeletal muscle. Comput Struct Biotechnol J 14: 20-27, 2015.

9. Fuller HR, Graham LC, Llavero Hurtado M and Wishart TM: Understanding the molecular consequences of inherited muscular dystrophies: Advancements through proteomic experimentation. Expert Rev Proteomics 13: 659-671, 2016.

10. Guiraud S, Aartsma-Rus A, Vieira NM, Davies KE, van Ommen GJ and Kunkel LM: The pathogenesis and therapy of muscular dystrophies. Annu Rev Genomics Hum Genet 16: 281-308, 2015.

11. Doran P, Martin G, Dowling P, Jockusch H and Ohlendieck K: Proteome analysis of the dystrophin-deficient MDX diaphragm reveals a drastic increase in the heat shock protein cvHSP. Proteomics 6: 4610-4621, 2006.

12. Rayavarapu S, Coley W, Cakir E, Jahnke V, Takeda S, Aoki Y, Grodish-Dressman H, Jaiswal JK, Hoffman EP, Brown KJ, et al: Identification of disease specific pathways using in vivo SILAC proteomics in dystrophin deficient $\mathrm{mdx}$ mouse. Mol Cell Proteomics 12: 1061-1073, 2013.

13. Holland A, Henry M, Meleady P, Winkler CK, Krautwald M, Brinkmeier $\mathrm{H}$ and Ohlendieck K: Comparative label-free mass spectrometric analysis of mildly versus severely affected mdx mouse skeletal muscles identifies Annexin, lamin, and Vimentin as universal dystrophic markers. Molecules 20: 11317-11344, 2015.

14. Holland A, Dowling P, Meleady P, Henry M, Zweyer M, Mundegar RR, Swandulla D and Ohlendieck K: Label-free mass spectrometric analysis of the mdx-4cv diaphragm identifies the matricellular protein periostin as a potential factor involved in dystrophinopathy-related fibrosis. Proteomics 15: 2318-2331, 2015.

15. Holland A, Carberry S and Ohlendieck K: Proteomics of the dystrophin-glycoprotein complex and dystrophinopathy. Curr Protein Pept Sci 14: 680-697, 2013.

16. Dowling P, Holland A and Ohlendieck K: Mass spectrometry-based identification of muscle-associated and muscle-derived proteomic biomarkers of dystrophinopathies. J Neuromuscul Dis 1: 15-40, 2014.

17. Murphy S, Dowling P and Ohlendieck K: Comparative skeletal muscle proteomics using two-dimensional gel electrophoresis. Proteomes 4: 27, 2016.

18. Lewis $\mathrm{C}$ and Ohlendieck K: Mass spectrometric identification of dystrophin isoform Dp427 by on-membrane digestion of sarcolemma from skeletal muscle. Anal Biochem 404: 197-203, 2010.

19. Yoon JH,Johnson E, Xu R,MartinLT, Martin PT and MontanaroF: Comparative proteomic profiling of dystroglycan-associated proteins in wild type, mdx, and Galgt 2 transgenic mouse skeletal muscle. J Proteome Res 11: 4413-4424, 2012. 
20. Murphy S, Henry M, Meleady P, Zweyer M, Mundegar RR, Swandulla D and Ohlendieck K: Simultaneous pathoproteomic evaluation of the dystrophin-glycoprotein complex and secondary changes in the $\mathrm{mdx}-4 \mathrm{cv}$ mouse model of Duchenne muscular dystrophy. Biology (Basel) 4: 397-423, 2015

21. Murphy S, Zweyer M, Mundegar RR, Henry M, Meleady P, Swandulla D and Ohlendieck K: Concurrent label-free mass spectrometric analysis of dystrophin isoform Dp427 and the myofibrosis marker collagen in crude extracts from $\mathrm{mdx}-4 \mathrm{cv}$ skeletal muscles. Proteomes 3: 298-327, 2015.

22. Turk R, Hsiao JJ, Smits MM, Ng BH, Pospisil TC, Jones KS, Campbell KP and Wright ME: Molecular signatures of membrane protein complexes underlying muscular dystrophy. Mol Cell Proteomics 15: 2169-2185, 2016.

23. Bonilla E, Samitt CE, Miranda AF, Hays AP, Salviati G, DiMauro S, Kunkel LM, Hoffman EP and Rowland LP: Duchenne muscular dystrophy: Deficiency of dystrophin at the muscle cell surface. Cell 54: 447-452, 1988.

24. Hoffman EP, Knudson CM, Campbell KP and Kunkel LM Subcellular fractionation of dystrophin to the triads of skeletal muscle. Nature 330: 754-758, 1987.

25. Knudson CM, Hoffman EP, Kahl SD, Kunkel LM and Campbell KP: Evidence for the association of dystrophin with the transverse tubular system in skeletal muscle. J Biol Chem 263 8480-8484, 1988.

26. Salviati G, Betto R, Ceoldo S, Biasia E, Bonilla E, Miranda AF and Dimauro S: Cell fractionation studies indicate that dystrophin is a protein of surface membranes of skeletal muscle. Biochem J 258: 837-841, 1989.

27. Ohlendieck K, Ervasti JM, Snook JB and Campbell KP: Dystrophin-glycoprotein complex is highly enriched in isolated skeletal muscle sarcolemma. J Cell Biol 112: 135-148, 1991

28. Ohlendieck K and Campbell KP: Dystrophin constitutes 5\% of membrane cytoskeleton in skeletal muscle. FEBS Lett 283 : 230-234, 1991

29. Ohlendieck K and Campbell KP: Dystrophin-associated proteins are greatly reduced in skeletal muscle from mdx mice. J Cell Biol 115: 1685-1694, 1991.

30. Ohlendieck K, Matsumura K, Ionasescu VV, Towbin JA, Bosch EP, Weinstein SL, Sernett SW and Campbell KP Duchenne muscular dystrophy: Deficiency of dystrophin-associated proteins in the sarcolemma. Neurology 43: 795-800, 1993.

31. Dowling P, Lohan J and Ohlendieck K: Comparative analysis of Dp427-deficient mdx tissues shows that the milder dystrophic phenotype of extraocular and toe muscle fibres is associated with a persistent expression of beta-dystroglycan. Eur J Cell Biol 82: 222-230, 2003

32. Cluchague N, Moreau C, Rocher C, Pottier S, Leray G, Cherel Y and Le Rumeur E: beta-Dystroglycan can be revealed in microsomes from mdx mouse muscle by detergent treatment. FEBS Lett 572: 216-220, 2004

33. Daval S, Rocher C, Cherel Y and Le Rumeur E: Several dystrophin-glycoprotein complex members are present in crude surface membranes but they are sodium dodecyl sulphate invisible in $\mathrm{KCl}$-washed microsomes from mdx mouse muscle. Cell Mol Biol Lett 15: 134-152, 2010.

34. Ohlendieck K: On-membrane digestion technology for muscle proteomics. J Membr Sep Technol 2: 1-12, 2013.

35. Ohlendieck K: Organelle proteomics in skeletal muscle biology. J Integr OMICS 2: 27-38, 2012.

36. Zubrzycka-Gaarn EE, Bulman DE, Karpati G, Burghes AH, Belfall B, Klamut HJ, Talbot J, Hodges RS, Ray PN and Worton RG: The Duchenne muscular dystrophy gene product is localized in sarcolemma of human skeletal muscle. Nature 333 466-469, 1988.

37. Watkins SC, Hoffman EP, Slayter HS and Kunkel LM: Immunoelectron microscopic localization of dystrophin in myofibres. Nature 333: 863-866, 1988

38. Cullen MJ, Walsh J, Nicholson LV and Harris JB: Ultrastructural localization of dystrophin in human muscle by using gold immunolabelling. Proc R Soc Lond B Biol Sci 240: 197-210, 1990.

39. Carpenter S, Karpati G, Zubrzycka-Gaarn E, Bulman DE, Ray PN and Worton RG: Dystrophin is localized to the plasma membrane of human skeletal muscle fibers by electron-microscopic cytochemical study. Muscle Nerve 13: 376-380, 1990.

40. Staunton L, Jockusch H, Wiegand C, Albrecht T and Ohlendieck K: Identification of secondary effects of hyperexcitability by proteomic profiling of myotonic mouse muscle. Mol Biosyst 7: 2480-2489, 2011.
41. Murray BE and Ohlendieck K: Cross-linking analysis of the ryanodine receptor and alpha1-dihydropyridine receptor in rabbit skeletal muscle triads. Biochem J 324: 689-696, 1997.

42. Bradford MM: A rapid and sensitive method for the quantitation of microgram quantities of protein utilizing the principle of protein-dye binding. Anal Biochem 72: 248-254, 1976.

43. Rosemblatt $M$, Hidalgo $C$, Vergara $C$ and Ikemoto $N$ : Immunological and biochemical properties of transverse tubule membranes isolated from rabbit skeletal muscle. J Biol Chem 56: 8140-8148, 1981.

44. Sharp AH,Imagawa T,Leung AT and Campbell KP: Identification and characterization of the dihydropyridine-binding subunit of the skeletal muscle dihydropyridine receptor. J Biol Chem 262: 12309-12315, 1987.

45. Muñoz P, Rosemblatt M, Testar X, Palacín M and Zorzano A: Isola tion and characterization of distinct domains of sarcolemma and T-tubules from rat skeletal muscle. Biochem J 307: 273-280, 1995.

46. Staunton L and Ohlendieck K: Mass spectrometric characterization of the sarcoplasmic reticulum from rabbit skeletal muscle by on-membrane digestion. Protein Pept Lett 19: 252-263, 2012.

47. Ohlendieck K: Characterisation of the dystrophin-related protein utrophin in highly purified skeletal muscle sarcolemma vesicles. Biochim Biophys Acta 1283: 215-222, 1996.

48. Vretblad P: Purification of lectins by biospecific affinity chromatography. Biochim Biophys Acta 434: 169-176, 1976.

49. Luque-Garcia JL, Zhou G, Sun TT and Neubert TA: Use of nitrocellulose membranes for protein characterization by matrix-assisted laser desorption/ionization mass spectrometry. Anal Chem 78: 5102-5108, 2006.

50. Luque-Garcia JL, Zhou G, Spellman DS, Sun TT and Neubert TA: Analysis of electroblotted proteins by mass spectrometry: Protein identification after western blotting. Mol Cell Proteomics 7: 308-314, 2008.

51. Luque-Garcia JL and Neubert TA: On-membrane tryptic digestion of proteins for mass spectrometry analysis. Methods Mol Biol 536: 331-341, 2009.

52. Shevchenko A, Tomas H, Havlis J, Olsen JV and Mann M: In-gel digestion for mass spectrometric characterization of proteins and proteomes. Nat Protoc 1: 2856-2860, 2006.

53. Murphy S, Dowling P, Zweyer M, Mundegar RR, Henry M, Meleady P, Swandulla D and Ohlendieck K: Proteomic analysis of dystrophin deficiency and associated changes in the aged mdx-4cv heart model of dystrophinopathy-related cardiomyopathy. J Proteomics 145: 24-36, 2016.

54. Liu Y, Bouhenni RA, Dufresne CP, Semba RD and Edward DP Differential expression of vitreous proteins in young and mature New Zealand white rabbits. PLoS One 11: e0153560, 2016.

55. Ryan M, Butler-Browne G, Erzen I, Mouly V, Thornell LE, Wernig A and Ohlendieck K: Persistent expression of the alpha1S-dihydropyridine receptor in aged human skeletal muscle: Implications for the excitation-contraction uncoupling hypothesis of sarcopenia. Int J Mol Med 11: 425-434, 2003.

56. Glover L, Heffron JJ and Ohlendieck K: Increased sensitivity of the ryanodine receptor to halothane-induced oligomerization in malignant hyperthermia-susceptible human skeletal muscle. J Appl Physiol 1985 96: 11-18, 2004.

57. Staunton L, Zweyer M, Swandulla D and Ohlendieck K: Mass spectrometry-based proteomic analysis of middle-aged vs. aged vastus lateralis reveals increased levels of carbonic anhydrase isoform 3 in senescent human skeletal muscle. Int J Mol Med 30: 723-733, 2012.

58. Chartier A, Klein P, Pierson S, Barbezier N, Gidaro T, Casas F, Carberry S, Dowling P, Maynadier L, Bellec M, et al: Mitochondrial dysfunction reveals the role of mRNA poly(A) tail regulation in oculopharyngeal muscular dystrophy pathogenesis. PLoS Genet 11: e1005092, 2015.

59. Drissi R, Dubois ML and Boisvert FM: Proteomics methods for subcellular proteome analysis. FEBS J 280: 5626-5634, 2013

60. Breckels LM, Gatto L, Christoforou A, Groen AJ, Lilley KS and Trotter MW: The effect of organelle discovery upon sub-cellular protein localisation. J Proteomics 88: 129-140, 2013

61. Mueller SJ, Hoernstein SN and Reski R: Approaches to characterize organelle, compartment, or structure purity. Methods Mol Biol 1511: 13-28, 2017.

62. Larance M and Lamond AI: Multidimensional proteomics for cell biology. Nat Rev Mol Cell Biol 16: 269-280, 2015.

63. Lefort N, Yi Z, Bowen B, Glancy B, De Filippis EA, Mapes R, Hwang H, Flynn CR, Willis WT, Civitarese A, et al: Proteome profile of functional mitochondria from human skeletal muscle using one-dimensional gel electrophoresis and HPLC-ESI-MS/ MS. J Proteomics 72: 1046-1060, 2009. 
64. Lombardi A, Silvestri E, Cioffi F, Senese R, Lanni A, Goglia F de Lange $\mathrm{P}$ and Moreno M: Defining the transcriptomic and proteomic profiles of rat ageing skeletal muscle by the use of a cDNA array, 2D- and Blue native-PAGE approach. J Proteomics 72: 708-721, 2009.

65. Ferreira R, Vitorino R, Alves RM, Appell HJ, Powers SK, Duarte JA and Amado F: Subsarcolemmal and intermyofibrillar mitochondria proteome differences disclose functional specializations in skeletal muscle. Proteomics 10: 3142-3154, 2010.

66. Liu Z, Du X, Deng J, Gu M,Hu H, Gui M, Yin CC and ChangZ: The interactions between mitochondria and sarcoplasmic reticulum and the proteome characterization of mitochondrion-associated membrane from rabbit skeletal muscle. Proteomics 15: 2701-2704, 2015.

67. Liu Z, Du X, Yin C and Chang Z: Shotgun proteomic analysis of sarcoplasmic reticulum preparations from rabbit skeletal muscle. Proteomics 13: 2335-2338, 2013.

68. Vitorino R, Ferreira R, Neuparth M, Guedes S, Williams J, Tomer KB, Domingues PM, Appell HJ, Duarte JA and Amado M: Subcellular proteomics of mice gastrocnemius and soleus muscles. Anal Biochem 366: 156-169, 2007.

69. Toigo M, Donohoe S, Sperrazzo G, Jarrold B, Wang F, Hinkle R, Dolan E, Isfort RJ and Aebersold R: ICAT-MS-MS time course analysis of atrophying mouse skeletal muscle cytosolic subproteome. Mol Biosyst 1: 229-241, 2005.
70. Maughan DW, Henkin JA and Vigoreaux JO: Concentrations of glycolytic enzymes and other cytosolic proteins in the diffusible fraction of a vertebrate muscle proteome. Mol Cell Proteomics 4 : 1541-1549, 2005.

71. Ohlendieck K: Proteomics of skeletal muscle glycolysis. Biochim Biophys Acta 1804: 2089-2101, 2010.

72. Gannon J, Doran P, Kirwan A and Ohlendieck K: Drastic increase of myosin light chain MLC-2 in senescent skeletal muscle indicates fast-to-slow fibre transition in sarcopenia of old age. Eur J Cell Biol 88: 685-700, 2009.

73. Holland A and Ohlendieck K: Proteomic profiling of the contractile apparatus from skeletal muscle. Expert Rev Proteomics 10: 239-257, 2013.

74. Ohlendieck K: Towards an understanding of the dystrophin-glycoprotein complex: Linkage between the extracellular matrix and the membrane cytoskeleton in muscle fibers. Eur J Cell Biol 69: 1-10, 1996.

75. Murray BE, Froemming GR, Maguire PB and Ohlendieck K: Excitation-contraction-relaxation cycle: Role of $\mathrm{Ca}^{2+}$-regulatory membrane proteins in normal, stimulated and pathological skeletal muscle (Review). Int J Mol Med 1: 677-687, 1998. 